\title{
Medicines management in the Philippine public sector during the response to Haiyan
}

\author{
Roderick Salenga, ${ }^{\text {ab }}$ Yolanda Robles, ${ }^{a}$ Monet Loquias, ${ }^{a}$ Francis Capulea and Anna Melissa Guerreroc \\ Correspondence to Roderick Salenga (email: salengar@wpro.who.int or ericsalenga@gmail.com).
}

Introduction: Health service delivery in the Philippines is constantly challenged by disasters and emergencies. This descriptive study documented existing policies for medicines management in the Philippines and then assessed these in the public sector response post-Haiyan.

Method: We used desk a review of existing laws, regulations and related issuances and a series of interviews of key informants from various national and local health agencies.

Results: We found that while numerous national policies covered critical aspects of medicines management, implementation post-Haiyan was problematic at all levels of the decentralized health-care system. We identified issues of quantification, warehousing, distribution, utilization monitoring and disposal. Donated medicines also added additional burden for storage and disposal, especially for expired and unwanted medicines.

Discussion: While the process of managing medicines during disasters did not differ greatly from non-emergency situations, the Haiyan experience highlighted the system's weaknesses. With the current gaps in implementation, as well as the logistical obstacles brought about by disasters, there is a need to have integrated mechanisms for medicines management in the Philippines. This assessment provided an important opportunity to review the medicines management policies at national and local levels.

$\mathrm{M}$ edicines management is the entire process of how medicines are selected, procured, delivered, prescribed, administered and reviewed to optimize the contribution they make to producing informed and desired outcomes of patient care. ${ }^{1}$ In the Philippines, medicines management occurs at all levels of government and is different during emergency and non-emergency times.

Health service delivery in the Philippines has been repeatedly disrupted as a result of disasters and emergencies - particularly so after Typhoon Haiyan in November 2013. The objectives of this study were to document existing policies for medicines management in the Philippines during emergency and non-emergency periods and to assess the public sector medicines management system in Haiyan-affected areas during the response.

\section{METHODS}

This qualitative study used a desk review of existing regulations on medicines management, plus 39 semistructured interviews with heads and/or authorized representatives of the following organizations: national agencies $(n=5)$, regional Centers for Health and Development $(n=3)$, regional warehouse facilities $(n=3)$, Department of Health (DOH)-retained hospitals $(n=3)$, provincial and district hospitals $(n=10)$, provincial and city health offices $(n=4)$, rural health units $(n=5)$ and village health stations $(n=6)$. All local health facilities were from the most severely hit regions (Regions 6, 7 and 8). Questions asked were mainly on the processes implemented in managing medicines during non-emergency and emergency situations. The interviews were conducted approximately one year after Haiyan between September and October 2014. 
Data gathered from the key informant interviews were transcribed verbatim and subjected to content analysis using interpretive techniques such as coding and recursive abstraction.

\section{RESULTS}

\section{Existing policies}

\section{Medicines for regular (non-emergency) programmes}

$\mathrm{DOH}$ is the governing agency mandated to provide national policy direction, plans, technical standards and guidelines for health. ${ }^{2}$ Local government units (LGUs) are granted autonomy and responsibility for their own health services but receive guidance from the $\mathrm{DOH}$ through their regional offices (ROs). Procurement of medicines by both national and local governments is through competitive bidding process. ${ }^{3}$

$\mathrm{DOH}$ is primarily responsible for the management of medicines for vertical programmes (tuberculosis, etc.), medicines access programmes (cancer, etc.) and for emergencies and disasters. These programmes are independently managed by several offices within the $\mathrm{DOH}$. Medicines are distributed through the RO to both the DOH and health facilities managed by LGUs hospitals (provincial, city and district), rural health units and village health stations. LGUs manage their procured medicines.

The push method predominantly governs procurement and distribution planning in the public sector. In this method, supply sources at one level in the system determine what types and quantities of medicines will be delivered to lower levels. ${ }^{4}$

\section{Medicines during emergencies and disasters}

Medicines in the DOH Package List for Emergencies and Disasters are managed by the Health Emergency Management Staff (HEMS). These medicines serve to augment supplies at the local health facilities. Where possible, immediately pre-disaster, HEMS estimates the types and quantities of medicines which may be required for response and recovery efforts at the regional level. These are then consolidated into a procurement plan.

Once a supplier is approved by a central office for bids and awards, the medicines are delivered to the $\mathrm{DOH}$ and samples are collected by Food and Drug Administration (FDA) for testing. The Materials Management Division then distributes the medicines to the ROs, which in turn distribute them to LGUs. LGUs will allocate to their respective local health facilities.

Local governments are permitted to make additional emergency purchases. This emergency procurement does not enter the usual bidding process, rather it only requires the approval of the local chief executive (e.g. municipal mayor).

\section{Administrative issuances}

There are four administrative orders (AOs) that relate to medicines management during emergencies and disasters. AO 2012-0013 stipulates that all government agencies must allocate at least $5 \%$ of their maintenance and other operational budget for logistics during emergencies and disasters. ${ }^{5}$ AO 2004-0168 defines the rules of engagement and sharing of resources and responsibilities for provision of medical services, specifying the DOH as the lead agency. ${ }^{6}$ The other two AOs outline the responsibilities of different institutions in ensuring the availability of medicines, instructions for donated medicines and how any warehoused supplies (before disaster) may be used for emergencies and disasters (AO 2003-54A ${ }^{7}$ and AO 2007-0017 $)$.

After confirming that international donations are listed on the national formulary, initial clearance is provided by the Bureau of International Health Cooperation. FDA provides the final clearance before the Bureau of Customs releases the items.

\section{Assessment of medicines management post-Haiyan}

\section{Availability of medicines}

Lack of coordination among facilities and ineffective feedback mechanisms during the response to Haiyan were consistently reported by participants. Management functions were exercised at all levels by different agencies and individuals. For national programmes, medicines continued to be managed independently by each programme group. At the same time, LGUs procured their own medicines supply. Neither national nor local sources were able to track stock levels accurately. Not all donated medicines were registered at the $\mathrm{DOH}$. 
The National Online Stock Inventory Reporting System, developed in 2007 to monitor the availability of medicines in the public sector, was not particularly helpful during response and recovery efforts. It required internet connectivity, and electricity was not restored to many affected areas until four months postHaiyan.

\section{Distribution of medicines}

Post-Haiyan, it was reported that medicines were delivered either to the $\mathrm{DOH}$ central and regional warehouses or directly to LGU health facilities, depending on the agreement made with suppliers at the time. These arrangements made coordination between and among programmes difficult and also made the mobilization of available medicines an inefficient process. Tracking the movement of medicines was not standardized. For most of the national programmes, distribution was considered complete once medicines were delivered to a regional warehouse. This was despite there often being limited qualified personnel to handle medicines once they had been delivered to the warehouse.

Post-Haiyan, the push method was inadequate as the quantities of medicines distributed were not based on need; therefore, both stock-outs and overstocking were reported. Many donated medicines were distributed by various groups at different levels of the health-care system and at different sites without a national control mechanism.

\section{Monitoring utilization of medicines}

There was no unified recording system for monitoring medicines distribution at any level; therefore, the integration of data and accessing real-time information of stock levels were difficult. Many facilities initiated their own manual process of recording medicines consumption.

\section{Disposal of medicines}

It was reported that on several occasions, national policies for accepting donations were not followed, which led to the acceptance of large quantities of short-dated, expired and unnecessary medicines. These occupied a lot of space in the already crowded warehouses and created an additional burden to dispose of them.

\section{DISCUSSION}

The Philippines has a complex medicines supply system; while the process of managing medicines during disasters is not greatly different than the usual practice, the response to Haiyan highlighted the system's weaknesses. Existing problems at various stages of the medicines management cycle were amplified.

Clearly defined policies at the national level did not translate well to the LGU level. When medicines reached regional facilities and the distribution was considered complete by the $\mathrm{DOH}$, there was a failure to recognize that most regional facilities did not have mechanisms in place to distribute stocks to target recipients. Given the damage caused by Haiyan, there was no alternative for the physical transfer of stock so the medicines remained in storage. Storage facilities were inadequate due to the damage to existing facilities and the massive influx of donated medicines.

National guidelines for accepting donations and handling pharmaceutical wastes were not fully implemented in health facilities. The absence of reliable drug consumption data also prevented authorities from moving to a pull system of distribution during recovery.

This study has limitations. The findings cannot be generalized to all regions and LGUs due to the participants being from selected regions, and their experiences and opinions may not be representative. The impact of the disaster on the medicines management system was unable to be quantified. Because there was no formal assessment before Haiyan, pre- and post- comparisons were not possible. However, as Haiyan was worse than any other typhoon in the country's recorded history, the context of the study is truly exceptional.

\section{CONCLUSION}

This study found that while national policies on managing medicines during disasters were in place, implementing these in a decentralized and devastated health system was difficult. The lack of coordinated processes and tools 
to facilitate easy and timely monitoring of medicines availability, distribution and consumption led to either overstocking or understocking of medicines. Processing large volumes of donated medicines combined with a decentralized procurement system in a post-disaster setting meant that storage facilities were overwhelmed and had limited skilled human resources. Receiving short-dated, near-expiry and unnecessary items which could not be easily distributed caused an additional burden to the health system as they needed to be safely disposed.

An integrated system that bridges the gap between the national government and various health facilities should be in place to ensure equitable access to medicines and reduce resource wastages in times of disasters.

\section{Conflicts of interests}

None declared.

\section{Funding}

This work was funded by the WHO Representaitive Office in the Philippines.

\section{Acknowledgements}

The authors wish to acknowledge Mr Jean-Michel Cann, Ms Shasta Daisy Triumfante, Ms Justine Urias and Mr Philip Edward Balbas.

\section{References}

1. A spoonful of sugar - medicines management in NHS hospitals. United Kingdom, Audit Commission, 2011 (http://archive.audit-commission.gov.uk/auditcommission/ sitecollectiondocuments/AuditCommissionReports/National Studies/nrspoonfulsugar.pdf, accessed 8 April 2015).

2. Republic Act No. 7160: An act providing for a Local Government Code of 1991. Quezon City, Eighth Congress of the Philippines, 1991 (http://www.lawphil.net/statutes/repacts/ra1991/ra_7160_ 1991.html, accessed 12 August 2015).

3. Republic Act No. 9184: An act providing for the modernization, standardization and regulation of the procurement activities of the government and for other purposes. Quezon City, Twelfth Congress of the Philippines, 2002 (http://www. bsp.gov.ph/downloads/procurement/ra9184.pdf, accessed 12 August 2015).

4. Management of drugs at health centre level: training manual. Brazzaville, World Health Organization Regional Office for Africa, 2004 (http://apps.who.int/medicinesdocs/pdf/s7919e/s7919e. pdf, accessed 12 August 2015).

5. Administrative Order No. 2012-0013: Policy and guidelines on logistics management in emergencies and disasters (2 July 2012). Manila, Department of Health, 2012 (http:// recordsvr.doh.gov.ph/appnet/public/p/ai/searchall.htm, accessed 3 September 2015).

6. Administrative Order No. 2004-0168: National policy on health emergencies and disasters (9 September 2004). Manila, Department of Health, 2004 (http://recordsvr.doh.gov.ph/appnet/ public/p/ai/searchall.htm, accessed 3 September 2015).

7. Administrative Order No. 2003-54A: Guidelines on the processing and clearance of importations through donations by the Department of Health (6 June 2003). Manila, Department of Health, 2003 (http://www.fda.gov.ph/attachments/ article/153563/AO\%2054-A\%20s.\%202003.pdf, accessed 3 September 2015).

8. Administrative Order No. 2007-0017: Policies and guidelines in the conduct of foreign and surgical missions (FSMM) in the Philippines (28 May 2007). Manila, Department of Health, 2007 (http://files.ennonline.net/attachments/412/ao2007-0017.pdf, accessed 3 September 2015). 